\title{
GESTÃO DA ENGENHARIA DENTRO DE DIFERENTES ESTRUTURAS DE PROJETOS DE MINERAÇÃO*
}

\author{
Wagner Fidelis Brum ${ }^{1}$ \\ Antônio Eduardo Clark Peres ${ }^{2}$ \\ Amauri José Cândido 3
}

\section{Resumo}

Os desafios atuais no mercado de mineração de ferro requerem uma gestão de engenharia cada vez mais dinâmica a fim de tornar viáveis novos projetos, os quais contemplam reservas com minérios mais profundos, mais compactos e com teores menores do metal alvo. Além disso, estudos de viabilidade de alta complexidade têm como objetivo tornar rentáveis operações inseridas em ambientes repletos de restrições. Neste trabalho serão discorridas diferentes formas de se estruturar a engenharia a fim de atender tanto a projetos pequenos, quanto médios ou grandes. Nesse momento serão abordadas vantagens e desvantagens de cada modelo, bem como serão sugeridas estruturas para que se atinja uma boa qualidade de engenharia dentro do custo esperado.

Palavras-chave: Estrutura funcional; Engenharia; Projetos de mineração; Modelos.

\section{ENGINEERING MANAGEMENT WITHIN DIFFERENT STRUCTURES OF MINING PROJECTS}

\section{Abstract}

Current Challenges Within Iron Ore Market Require An Increasingly And Dynamic Engineering Management To Make Feasible New Projects. It Is Expected That Future Projects Will Normally Comprise A Lower Quality Of The Reserves, Which Go Deeper And Deeper, Thus Finding A Harder Rock, Resulting In Lower Content Of The Target Metal Inside The Mined Ore, And Finally Demanding Complex Feasibility Studies, Which Aims To Create Profitable Operations In An Environment Full Of Restrictions. This Work Is Supposed To Describe Different Ways To Structure The Engineering In Order To Suit It To Smaller, Medium And Mega Projects. Then, Pros And Cons Of Applying Each Model Will Be Shown, As Well As Some Suggested Structures In Each Case To Reach A Reasonable Level Of Quality Under The Planned Budget.

Keywords: Organizational structure; Engineering; Mining projects; Model.

1 Engenheiro Especialista, Gerência de Engenharia e Implementação de Projetos, Samarco, Mina do Germano, Mariana, MG, Brasil.

2 Ph.D., Mestre, Professor DEMET, PPGEM, UFMG, Belo Horizonte, MG, Brasil.

3 Engenheiro Especialista, Gerência de Engenharia e Implementação de Projetos, Samarco, Mina do Germano, Mariana, MG, Brasil. 


\section{INTRODUÇÃO}

Assim como as demais grandes mineradoras mundiais, também a SAMARCO Mineração S.A. se baseia na metodologia FEL [1] para estruturar sua diretoria de estudo e execução de projetos, conforme sequência mostrada na Figura 1. A SAMARCO busca contemplar todas as áreas de conhecimento sugeridas pelo Guia PMBOK [2], e visa uma constante e gradativa evolução nos resultados dos projetos, enriquecida a partir da coleta e absorção do conhecimento gerado a partir das etapas de planejamento e construção de projetos já encerrados.

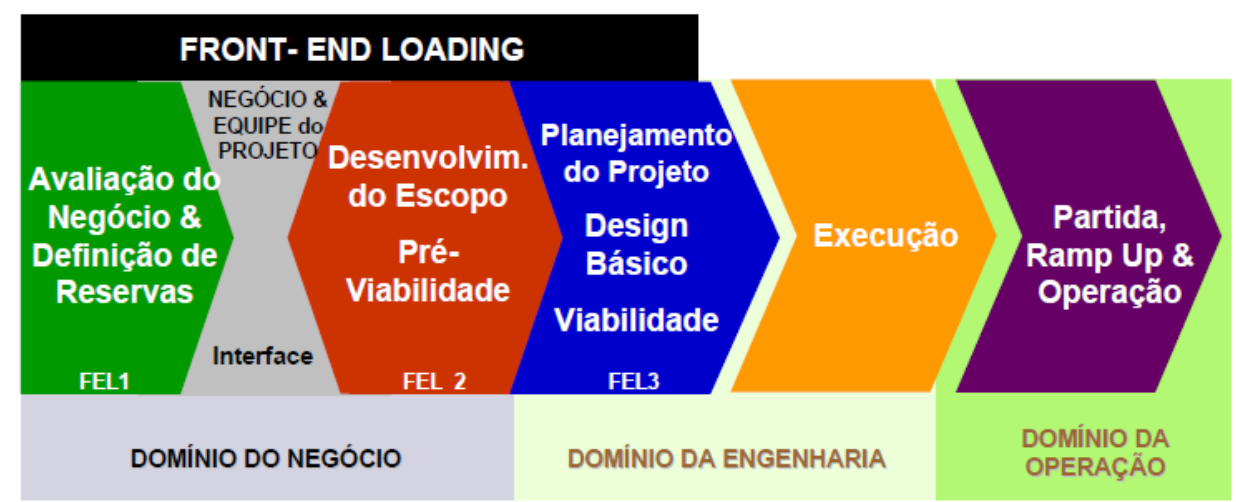

Figura 1 - Ciclo típico de um projeto de capital [1].

Ao longo deste ciclo a gestão de algumas áreas sempre merece especial atenção, as quais são: engenharia, planejamento, construção e contratos. O foco deste trabalho é mostrar como a gestão da engenharia pode ser estruturada dentro de um ambiente dinâmico, desafiador e, por tudo isso, motivador e estimulante. Em paralelo também será mostrada a importância do planejamento como ferramenta essencial para monitoramento e controle de todas as áreas de conhecimento [2].

A fim de contextualizar este descritivo, é fundamental mostrar como é definido o processo de gestão dos investimentos de capital da SAMARCO Mineração S.A., o que é feito a partir da caracterização do investimento [3], quando se identifica a necessidade ou a oportunidade de se criar um projeto. Na sequência é definida a classificação do mesmo quanto à motivação (alinhamento estratégico) e ao tipo (complexidade). O macrofluxo para investimentos de capital segue as boas práticas sugeridas pelo Guia PMBOK [2] e é apresentado na Figura 2.

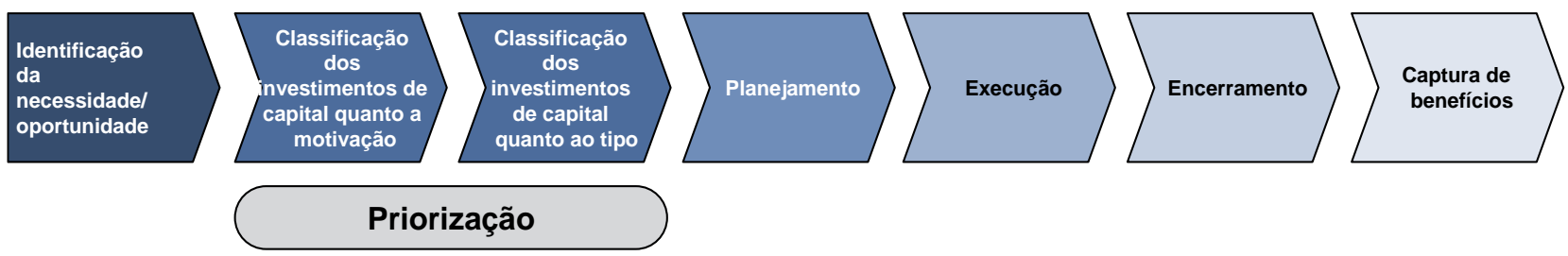

Figura 2 - Macrofluxo para investimentos de capital [3].

Em seguida é mostrado como é modelada a estrutura de gestão de engenharia na SAMARCO, a qual se baseia no tipo de projeto em questão, podendo esse ser classificado como "baseados em planta" (BP), de "engenharia central" (EC) ou "megaprojetos" (MP). Tal classificação tem referência no CAPEX inicialmente estimado e na complexidade do projeto. 
Projetos baseados em planta são projetos de menor complexidade, CAPEX mais baixo, e podem ser tratados diretamente pela área operacional que os iniciaram.

Projetos de engenharia central são criados pelas áreas operacionais, tendo o FEL 1 conduzido pelas mesmas. As fases seguintes, de FEL 2, de FEL 3 e de execução, são de responsabilidade da gerência de engenharia e implementação de projetos.

Megaprojetos são expansões de capacidade caracterizadas pela construção de novas usinas com CAPEX significativos, sendo planejadas e implementadas por uma equipe independente, a qual dispõe de dedicação exclusiva ao projeto.

Essa conceituação é importante, pois, é sabido que na indústria de extração e beneficiamento de minério de ferro há sempre projetos de capital que podem ser classificados como baseados em planta, de engenharia central, ou megaprojetos e merecerá tratamento diferenciado para cada tipo.

\section{OBJETIVO E METODOLOGIA}

O objetivo deste trabalho é descrever as estruturas de engenharia da Samarco Mineração $S / A$, as quais foram baseadas na metodologia de gerenciamento de projetos [3] e segundo as melhores práticas [2], a fim de atingir o sucesso em todas as etapas do projeto e uma efetiva melhora no negócio da empresa após a sua implementação. Naturalmente, essas estruturas têm seus pontos fortes e seus pontos fracos, estão em constante aprimoramento, tendo sido criadas para uma condição específica da realidade de mercado da SAMARCO e do segmento.

Serão descritas as diferentes estruturas de gestão de engenharia e a aplicabilidade dessas dentro da área de gerenciamento de projetos na SAMARCO. Ao final buscase apresentar esses modelos para que o trabalho faça referência a cada tipo de projeto, possibilitando que se conclua o que esperar de cada um. Considerando que cada empresa deve buscar sua própria identidade, espera-se que, a partir da leitura deste trabalho, caso o leitor esteja avaliando realizar uma adequação em sua estrutura de engenharia, o mesmo seja utilizado como referência para que a mesma atinja os entregáveis previstos.

\subsection{Gestão do Projeto conforme Tipo de Contrato}

Antes de abordar a influência dos tipos de contrato na gestão do projeto, é importante discorrer a respeito das mudanças históricas que vêm ocorrendo no mercado de projetos ao longo dos últimos 50 anos.

Nas décadas de 60 e 70, de uma forma geral, as grandes mineradoras tinham uma equipe própria de engenharia e de gerenciamento de projeto, enquanto empresas de projeto tinham profissionais que conheciam em detalhes os processos dos clientes.

Ao longo das décadas de 80 e 90 , o que se viu foi que as grandes mineradoras começaram a comprar no mercado tanto o desenvolvimento da engenharia quanto 0 gerenciamento dos projetos. Por outro lado, as empresas projetistas começaram a ter maior rotatividade em função de frequentes crises econômicas.

A partir do ano 2000, as grandes mineradoras começaram a utilizar empresas de gerenciamento de uma forma mais abrangente e toda estrutura de gerenciamento própria passou a ser organizada de forma a adequar a esse modelo. Empresas projetistas nacionais se tornaram alvo de grandes grupos multinacionais de engenharia e gerenciamento e acabaram sendo compradas, viabilizando uma rápida inserção dos mesmos no mercado nacional. Esses grupos globais trouxeram ao Brasil modelos amplamente utilizados no exterior, principalmente no Canadá e na 
Austrália, entre eles o modelo EPCM (Engenharia, Suprimentos, Construção e Gerenciamento; sigla em inglês), o que requer uma melhor definição do escopo no momento da aquisição, mas por outro lado demanda uma estrutura menos robusta por parte do cliente, visto que cabe a esse basicamente fiscalizar itens como: risco, escopo, prazo, custo, qualidade e recursos; conforme citado na Figura 3; bem como disciplinas fundamentais nas empresas de mineração, tais como: segurança, saúde, relacionamento com comunidade e meio-ambiente, entre outros.

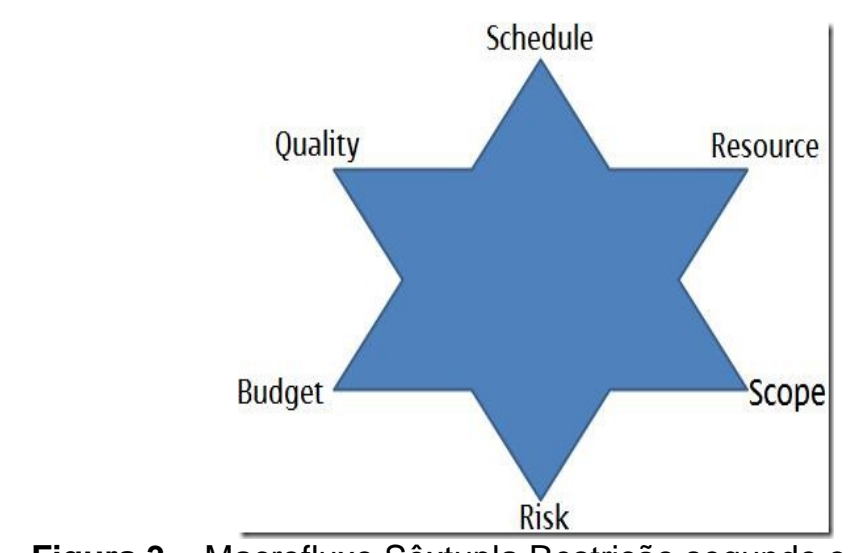

Figura 3 - Macrofluxo Sêxtupla Restrição segundo o PMBOK [2].

Dentro do cenário atual, de alta volatilidade do mercado comprador de minério de ferro, que ora torna viável, ora inviável, projetos de expansão ou novos projetos em condições bem mais desafiadoras que outrora, é fundamental observar três outros fatores críticos [5], mostrados na Figura 4.

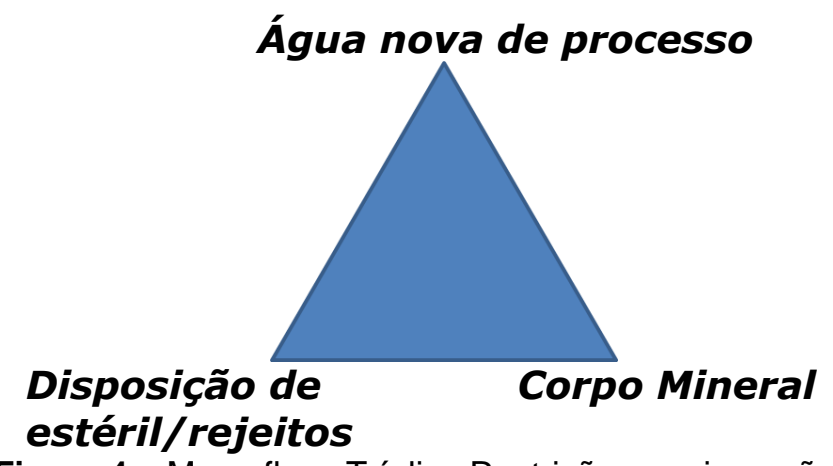

Figura 4 - Macrofluxo Tríplice Restrição na mineração [5].

Foi principalmente para atender a esta realidade, que a SAMARCO estruturou tanto sua engenharia quanto o planejamento, a fim de gerir seus projetos conforme suas necessidades específicas e buscando obter melhores entregas.

\subsection{Gestão do Planejamento e Controle dos Projetos}

Juntamente com a gestão da engenharia, é feita na SAMARCO uma constante gestão do planejamento e de controle dos projetos, desde sua fase inicial de estudos, passando pela execução, até o encerramento dos mesmos.

A metodologia e os processos presentes nos projetos baseados em planta e de engenharia central abordam os critérios e os procedimentos aplicáveis às fases de estudo e construção, e promovem subsídio às equipes de planejamento e das contratadas, com ferramentas e boas práticas para execução das atividades. 
O Planejamento se baseia em templates padronizados e modelos de cronograma desenvolvidos a partir da metodologia aplicável. Sempre ao final da fase atual, planeja-se a fase seguinte. As matrizes de riscos obtidas durante os seminários multidisciplinares de análise de riscos dos projetos, assim como os resultados da range analysis, são agregados ao cronograma de forma a garantir sua assertividade. Durante as fases de estudos são estipulados métodos de estimativas e é feita a elaboração de um cronograma detalhado da fase em que se encontra o projeto. São inseridas ainda atividades referentes à fase seguinte e suas respectivas durações. Ao final, o mesmo é aprovado pelo cliente interno e pelo sponsor proprietário do projeto. Está criada, então, a linha de base do cronograma [3], a partir da qual se estabelece a referência para o controle e monitoramento da fase seguinte do projeto. Durante a execução, o cronograma é enriquecido com informações provenientes da engenharia e dos pacotes adquiridos, e é validado junto aos executantes do projeto. A equipe de planejamento participa da elaboração dos editais de contratação, apresentando aos proponentes os requisitos de planejamento e marcos contratuais a serem seguidos no ciclo de execução, os quais serão cobrados durante toda fase.

A equipe de planejamento também participa das reuniões de abertura e das periódicas com as contratadas. Essa equipe controla e monitora o cronograma, emite relatórios, faz follow-up das listas de pendências, gerencia os mapas de acompanhamento de projetos e suprimentos, sendo ainda responsável pela elaboração da estrutura analítica do projeto (EAP), a qual é baseada na declaração de escopo, nos histogramas, nas curvas de avanço e no próprio cronograma.

O progresso físico é medido semanalmente. Mensalmente ou quinzenalmente relatase ao cliente interno e ao proprietário o progresso, os resultados e as próximas atividades do projeto. No gerenciamento de projeto o controle é tido como um investimento com retorno garantido, tendo em vista o potencial de ações a serem tomadas a partir do mesmo e o potencial de mitigação de perdas que esse oferece.

$\mathrm{Na}$ fase final de encerramento são coletados os dados e os indicadores que se constituirão nas evidências em relação ao plano de captura de benefícios planejado nas fases iniciais. É nesse momento que são registradas e divulgadas as lições aprendidas coletadas ao longo de todas as etapas, o que possibilitará que as mesmas se tornem rico banco de dados para demais projetos futuros.

Os controles são medidos por índices e avaliados periodicamente com base nos indicadores do projeto. Esses são focados em estimativas já validadas nas fases anteriores e mostram o avanço físico e financeiro da fase vigente. O controle é a melhor ferramenta para avaliar as entregas do projeto, visto que os indicadores são registrados nos relatórios gerenciais e visam auxiliar na gestão do projeto.

Os desvios são verificados a partir de KPl's (sigla em inglês para indicadores-chave do projeto) já definidos. E quando necessário, é proposto um eventual plano de ação para recuperação e replanejamento do projeto, mostrando, portanto, que o controle por ser uma ferramenta essencial de gestão.

Contudo, frequentemente o controle de um projeto é confundido com o monitoramento do mesmo. Porém, o monitoramento é passivo e o controle, ativo [4]. Para planejar é necessário ação, do contrário a equipe estará meramente "assistindo" ao projeto. Conclui-se então que, só existe o controle se existir autoridade para tal.

O controle dos projetos é tratado como um conjunto de dados que possibilita o exercício de prevenção e de influência direta com ações. Portanto, o controle tem dois objetivos: o de influenciar os resultados por meio de alteração das atividades e o de exercer responsabilidades sobre os ativos organizacionais. 
O sistema de controle total do projeto abrange o controle dos custos, da qualidade e do cronograma. Na visão geral dos controles, primeiramente é construída uma linha de base [4], que possibilita comparar o desempenho real frente ao planejado.

Em resumo pode-se concluir que, um planejamento bem elaborado e validado é uma premissa essencial para um bom controle do projeto.

\section{RESULTADOS E DISCUSSÃO}

Em quaisquer das três formas citadas, ou seja, projetos "baseados em planta" (BP), de "engenharia central" (EC) ou "megaprojetos" (MP), é sabido que tanto o planejamento, quanto a gestão de engenharia, são fatores críticos para se atingir bons resultados em um processo integrado [1].

As melhores práticas visam ajustar os custos ao mínimo necessário, dar uma maior acuidade ao cronograma e, também, prover melhor previsibilidade ao investimento, o que, ao final, se traduz em atender as expectativas do cliente [3]. A gestão da engenharia está diretamente vinculada ao mesmo, tanto quanto a gestão de planejamento e controle.

A gestão da linha de base do escopo [4] é outro fator essencial para o êxito do projeto. A partir da aprovação da engenharia básica é fundamental considerar que a mesma está "congelada", de outra forma, eventuais mudanças constantes colocarão em risco o sucesso do projeto durante sua execução [5]. A Figura 5 mostra como seria esse processo integrado para o controle e monitoramento do projeto como um todo [1].

E a terceira e última linha de base crítica, que deverá sempre merecer atenção da equipe de controle e da gestão de projeto como um todo é a de custos, que visa manter o CAPEX (sigla em inglês para gastos de investimentos) e juntas formam a famosa tríplice restrição [4], as quais estão evidenciadas na Figura 5.

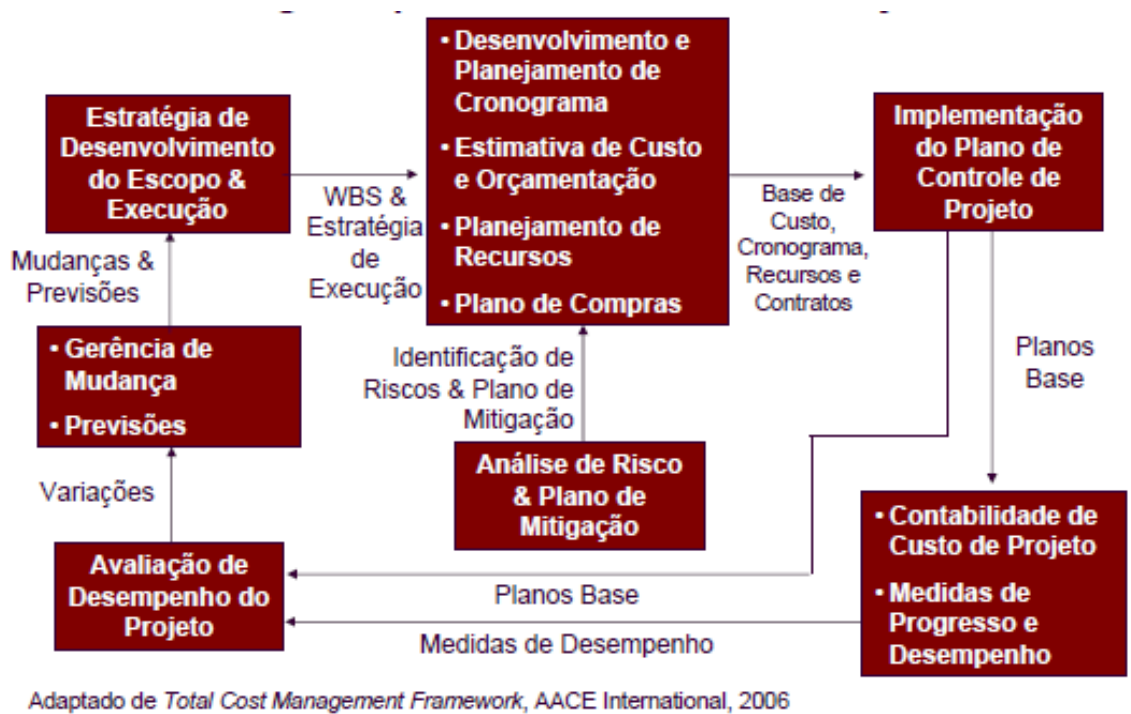

Figura 5 - Processo Integrado para controle total do projeto [1].

No que diz respeito a gerenciamento de projetos, a estrutura desses estará diretamente vinculada à estrutura organizacional da empresa que os conduz [4]. A estrutura organizacional preponderante na SAMARCO é a funcional, portanto as áreas estão dispostas conforme sua especialidade. Entretanto, há significativas diferenças na estrutura do projeto em função do tipo de projeto em questão, visto 
que, em megaprojetos haverá uma estrutura matricial dedicada ao mesmo, exigência dos acionistas para investimentos dessa monta.

Projetos baseados em planta são conduzidos geralmente pela engenharia de manutenção ou pela própria operação, visto que são de curta duração e de baixo CAPEX. A manutenção ou a operação alocam representantes multidisciplinares para a coordenação dos mesmos, que definem o escopo e compram o produto de engenharia no mercado, através de um pacote específico, ou através da projetista que esteja atuando na área (via contrato de longo prazo) para soluções simples.

Em quaisquer dos dois casos, a gestão da engenharia é feita em paralelo às atividades de rotina, ou seja, não há dedicação exclusiva ao projeto e nem um controle e um monitoramento específicos, pois há um portfólio com vários projetos.

As vantagens são a gestão por representantes que conhecem de perto as premissas, restrições e requisitos do projeto, com uma estrutura bem enxuta. As desvantagens são a falta de foco nos projetos e a não especialização dos responsáveis na metodologia de gerenciamento de projetos.

Projetos de engenharia central são conduzidos por uma gerência geral exclusiva de engenharia e implementação de projetos, a qual, apesar de possuir um corpo próprio pequeno, tem o apoio de uma empresa de gerenciamento. O representante da empresa é responsável pelo projeto desde FEL 2 até a conclusão da execução. $O$ produto de engenharia é adquirido no mercado, seja através de um pacote específico, ou através da utilização de projetista já contratada (via contrato de longo prazo vigente), e especializada em mineração ou no escopo em questão.

Em quaisquer dos dois casos, a gestão da engenharia é feita para um portfólio de projetos, ou seja, através de uma estrutura matricial da gerenciadora dentro da estrutura funcional do cliente. Esse portfólio contempla uma gama de projetos em fases distintas e de diferente natureza (geotecnia, estruturante, industrial, etc.) e apesar de não haver uma dedicação exclusiva a cada projeto, há um forte controle e monitoramento, o qual é conduzido segundo as melhores práticas [3].

As vantagens são a utilização de representantes que dominam os fundamentos de gerenciamento de projetos e possuem experiência em projetos similares já executados, bem como a manutenção de uma estrutura própria enxuta, a qual dá boa flexibilidade em função dos altos e baixos do mercado. A maior desvantagem é a necessidade de contar com a estrutura funcional da empresa, a qual nem sempre está preparada para apoiar conforme dinâmica do projeto. Outras desvantagens são a necessidade de se manter uma robusta estrutura da gerenciadora que apoia a gerência durante as fases de estudo e de construção; e a alta rotatividade de profissionais dessa gerenciadora, o que dificulta a condução do projeto e a retenção do histórico do projeto na empresa.

Megaprojetos são conduzidos por uma gerência geral de engenharia e implementação de projetos criada especificamente para o megaprojeto em questão, a qual é montada através da transferência de profissionais experientes da rotina para o projeto e complementados por especialistas em projeto da própria empresa e vindos do mercado. Também neste caso, esse grupo tem o suporte de uma empresa de gerenciamento, cuja equipe será em bem maior número que a equipe própria. Os representantes da empresa são responsáveis pelo projeto desde FEL 1 até a conclusão da execução. Ao final, esta equipe é dissolvida, sendo seus integrantes realocados em outro (mega) projeto ou retornam para a rotina, o que ocorre em estruturas tipicamente matriciais [4]. O produto de engenharia é adquirido no mercado através de pacotes específicos e controlado com equipe própria. 
A gestão da engenharia é feita por um grupo habituado a projetos, ou seja, há uma estrutura matricial para as diferentes disciplinas (de mecânica, estrutura metálica, elétrica, automação, geotecnia, instrumentação, processo, etc.) independente da estrutura funcional da empresa. Há uma dedicação exclusiva ao projeto e um forte controle e monitoramento, o qual é inclusive acompanhado de perto pelos acionistas, tendo em vista o elevado CAPEX e o esperado retorno [3].

As vantagens são a utilização de representantes especialistas de alto desempenho e a dedicação exclusiva da equipe, a qual conta, inclusive, com representantes da rotina que alimentam o projeto de informações ao longo de todo seu desenvolvimento, obedecendo ainda a uma metodologia própria para projetos dessa envergadura, a qual possibilita maior dinamismo e independência à equipe. As desvantagens são a necessidade de se dissolver a equipe após a entrega do projeto (e as consequências que essa ação provoca) e a dependência da equipe própria frente à gerenciadora, em muito maior número.

\section{CONCLUSÃO}

Durante os capítulos anteriores buscou-se mostrar a importância que tem adequar a gestão da engenharia e a gestão do planejamento e controle para estudo ou execução de projetos. A estrutura definida para tais disciplinas buscou, entre outras coisas, facilitar a gestão dos projetos e vencer o desafio de se implantar projetos dentro de ousadas metas que a dinâmica do mercado de mineração atualmente exige, face o elevado nível de maturidade exigido para cada tipo de projeto. Lembrando ainda que, a cada dia, aumenta a complexidade e a quantidade de partes interessadas (stakeholders, em inglês), que podem atuar a favor ou contra 0 projeto durante suas fases [4].

Ao se comparar este modelo com outras realidades é possível que se conclua que as estruturas são:

- Muito robustas, complexas ou redundantes;

- Apropriadas, mas ainda podem ser simplificadas;

- Uma ótima referência e podem ser replicadas em situações similares.

Seja qual for a conclusão do leitor, prevalece o objetivo deste trabalho de mostrar como é feita a gestão de engenharia e de planejamento e controle em uma empresa de mineração, que lida diariamente com pequenos, médios e grandes projetos a fim de se manter competitiva no mercado, e possibilitar que outras empresas, atuantes em mercados similares, possam pensar a respeito do assunto e avaliar eventuais possibilidades de mudanças internas.

\section{Agradecimentos}

Agradeço à Gerência de Engenharia e Implementação de Projetos da SAMARCO, ao professor Herman Sander Mansur, coordenador do PPGEM e ao CAPES/PROEX, pelo incentivo à pesquisa e ao desenvolvimento brasileiro.

\section{REFERÊNCIAS}

1 IPA ou Independent Project Analysis, Inc. (2011); Melhores Práticas para Projetos de Mineração. Curitiba: IPA Latino América, Material Didático do Curso.

2 PMI ou Project Management Institut, Inc. (2008); Guia PMBOK - Um Guia do Conhecimento em Gerenciamento de Projetos. 4를 Edição. Atlanta: PMI Book Service Center. 
3 Manual Governança e Gestão de Projetos Tipo EC da SAMARCO Mineração S.A. Gerência Geral de Projetos (GGP) - PMO (Escritório de Gerenciamento de Projetos) Revisão 1 - Fevereiro/2012.

4 Mulcahy R. (2009); Preparatório para o Exame de PMP®: Baseado na Quarta Edição do Guia PMBOK® - 6ª Edição: RMC Publications, Inc., USA, 536p.

5 Brum WF. (2013); Aplicação de metodologias de desenvolvimento de projetos para aumento da produção de concentrados de minério - Belo Horizonte: Escola de Engenharia da UFMG. Dissertação de Mestrado apresentada ao Programa de PósGraduação em Engenharia Metalúrgica, Materiais e de Minas da UFMG, 156p. 